Portland State University

PDXScholar

$5-1-1974$

\title{
Assessment of Course Impact on Child Care Worker Orientation: Worker Concerns Versus Child Concerns
}

Helen M. Banaka

Portland State University

Follow this and additional works at: https://pdxscholar.library.pdx.edu/open_access_etds

Part of the Social Work Commons

Let us know how access to this document benefits you.

Recommended Citation

Banaka, Helen M., "Assessment of Course Impact on Child Care Worker Orientation: Worker Concerns Versus Child Concerns" (1974). Dissertations and Theses. Paper 1751.

https://doi.org/10.15760/etd.1750

This Thesis is brought to you for free and open access. It has been accepted for inclusion in Dissertations and Theses by an authorized administrator of PDXScholar. Please contact us if we can make this document more accessible: pdxscholar@pdx.edu. 
ASSESSMENT OF COURSE IMPACT ON CHILD CARE WORKER ORIENTATION: WORKER CONCERNS VERSUS C.HILD CONCERNS

by

HELEN M. BANAKA

A research practicum submitted in partial fulfillment of the requirements for the degree of

MASTER OF SOC IAL WORK

Portland State University

1974 
TO THE OFFICE OF GRADUATE STUDIES AND RESEARCH:

The members of the Committee approve the research practicum of Helen M. Banaka presented May 1, 1974.

Bet tyaleond, havisor

Arthur Emlen

APPROVED :

Gordon Hearn, Dean, School of Social Work

David T. Clark, Dean of Graduate Studies and Research

May 1, 1974 
The writer wishes to acknowledge the following persons for their contributions to the writing of this research practicum. First, to Betty Leonard and to Arthur Emlen for contributing their time, expertise and advice. Second, to Mike Ebner, Ray Peterson and Linda Peterson, who provided inspiration to begin and encouragement to $f$ inish and, finally, to Bill Banaka who supported this project and continues to support all my efforts toward professional and personal growth. 
TABLE OF CONTENTS

PAGE

ACKNOWLEDGMENTS . . . . . . . . . . . . . . . . i i i

LIST OF TABLES. . . . . . . . . . . . . . . . . . . . . . $v$

LIST OF FIGURES . . . . . . . . . . . . . . . . . . . . $v i$

CHAPTER

I INTRODUCTION . . . . . . . . . . . . . . . . . 1

II METHOD....................... 5

Method of Analys is of Data......... 11

Method for Testing Reliability....... . 11

III RESULTS . . . . . . . . . . . . . . . . . . . . 15

IV DISCUSSION....................... 20

Recommendations . . . . . . . . . 22

REFERENCES . . . . . . . . . . . . . . . . 25

APPENDIX ......................... . . . 27 


\section{LIST OF TABLES}

TABLE

PAGE

I Reliability of Response Coding...........

II Pre- and Post-f's and $\bar{X}^{\prime}$ 's of Coded Answers and Preand Post $\bar{x}$ Score Differences ........ . . 16

111 Means of Difference Scores and Their t-Tests..... 18

IV Ratio Change Scores............. 19 


\section{LIST OF FIGURES}

FIGURE

PAGE

I Problem Solving Situation, PSS . . . . . . . .

II Problem Solving Situation, PSS-R..........

III Response Classes Used as Criteria for Coding the PSS and PSS-R ............... 
CHAPTER I

INTRODUCTION

This study proposes to examine the impact of an adult education course on the attitudes and orientation of child care workers. Therefore, the researcher has confined her discussion of the literature mainly to examples of research and theory developed in the area of adult education.

The values particular to adult education theory or androgogy, as as opposed to theories of pedagogy, the art and science of teaching children, are premised on assumptions about adult learners that differ from assumptions about how children learn (Knowles, 1970).

These assumptions are that as a person matures, 1) his selfconcept moves from one of being a dependent personality toward one of being a self-directing human being; 2) he accumulates a growing reservoir of experience that becomes an increasing resource for learning; 3 ) his readiness for learning becomes oriented increasingly to the tasks of his social roles; 4 ) his time perspective changes from one of postponed application of knowledge to immediacy of application, and accordingly his orientation toward learning shifts from one of subject centeredness to one of problem centeredness. (Pg. 39)

The conflicts involved in adult education evaluation and research have been reviewed (Knowles, 1970). A rigid theory of scientific method, an attitude of no evaluation, and confusion about how to accomplish really good research all appear to exist together. Knowles asserts that this kind of confusion has resulted in an underproduction of usable evaluation materials.

While Essert (1951) has remarked that adult education need not be subject to elaborate evaluation schemes as long as the student is enhanced by the experience others have taken a more conservative position. The importance of adhering to scientific method in evaluation research 
because of the responsibility involved in causing changes in human beings has been explored by Sabrosky (1966). Verner, Coolie \& Booth (1964), have suggested that anything less than the most rigorous scientific exploration might better be left undone. A systematic approach to evaluation to replace the more frequent hasty subjective judgements is urged by Thatcher (1963). The shortsightedness of adult educators who fail to take evaluation seriously has been discussed (Goodacre, 1967; Knowles, 1950).

A more recent view by knowles $(1970)$ is to hold on to the goal of scientific inquiry in adult education, while remaining cognizant of the limits inherent in adult education research. He maintains that given the variables of human behavior, it is difficult to prove that a desirable change has occured because of adult education; research procedures and measurement instruments for getting hard data out of adult education efforts have not been produced; scientific evaluation is expensive and policy makers are not always willing or able to support such efforts; and, because adult education is an open system, the worth of a program may better be evaluated by the client's satisfaction. It is this writer's opinion that these problems cited by knowles are not necessarily limited to the research of adult education but exist wherever changes in attitude are being measured.

Further examination of the literature yielded much on the philosophy of adult education and the design of programs. Much less appears on the actual assessment of change as a result of an adult education experience. Although, the Adult Education Journal asserts the situation is impreving and cites a content analysis of their periodical that shows 
an increase in research based articles and a decrease in program descriptions and statements of personal belief and experience from 1950 to 1971. (Dickenson \& Russel, 1971). Also, Dickenson E Rubidge (1973) have contributed to the development of standardized tests for learning outcomes of programs by designing a pre- and post-test assessment device.

Some studies that actually measure the effect of an adult education experience do appear. For example, increased reading comprehension as a result of adult remedial reading classes has been demonstrated (DiSalvi, 1971; Bryant, Bryant, Christianson and Fisher, 1971). In addition, it has been shown that teacher attitudes appear to be more modified by experience in teaching than by their training experience in a study regarding prejudice among literacy teachers by Johnson, Cortright E Cooper (1968). Eugene Watson has assessed interpersonal changes in adult students exposed to direct feedback situations (1969). Studies on the effect of parent education have shown increased awareness of child rearing knowledge (Endres E Evans, 1968; Robinson and Spraights, 1969).

Recently the field of adult education has joined the growing interest in the training of child care workers and the upgrading of child care work as a profession, as evidenced by the course being examined in this study. This researcher did not find literature pertaining to the training of child care workers by adult education programs, but hopes to contribute to that literature by doing this study. Meanwhile, important contributions in the assessment of child care worker performance have been made by Ebner (1968) in developing a functional analys is approach to child and worker behavior; and by Peterson (1973) in the design of a 
Child Care-Treatment Worker Self Assessment Scale.'

The purpose of this study was to assess the impact of an adult education course on the attitudes and or ientation (worker concerns versus child concerns) of child care workers. Therefore, it was necessary to use an instrument that would apply the course content to an experiential format. The reader will remember the value placed on the relationship between course content and the immediacy of application to real life experience in adult education process theory.

It was thought that the Problem Solving Situation would: 1) Examine the impact of the course content on attitudes and beliefs by allowing maximum expression around content related issues and 2) Would utilize maximum flexibility of response, while allowing course relevant scoring. The Problem Solving Situation proposed to accomplish the above by describing four brief situations in the area of course content and allowing the students to describe what they would experience and do in that situation. It was expected that the students' responses would accord with values and contents of the course.

'Based on response classes developed by Ebner, M. \& Murray, W., So You Want to Work With Kids, unpublished manuscript, 1974. 


\section{CHAPTER I I}

METHOD

Adult students taking an introductory course in Applied Techniques in Child Care and Treatment through the Oregon State System of Higher Education, Division of Continuing Education at Portland State University participated in a group study to evaluate the effect of the course. Accepted for the study were the 30 students who had taken both the preand the post-course assessment device, the Problem Solving Situation (PSS). Altogether 82 students took the course, but 52 potential subjects were not included because they had taken only one or neither of the assessment tests.

of the $30 \underline{\mathrm{ss}}, 6$ took the course in the Fall term of 1972,11 in the Winter term of 1973, and 13 were from the Spring term of 1973. Twelve of the Ss were male and 18 were female. All were taking the course for college credit, 17 for graduate credit and 13 for undergraduate credit. Twenty-seven of the subjects were employed as child care workers or were in child related positions on their jobs. Three of the ss were enrolled in the Graduate School of Social Work at Portland State University and had field placements in child related agencies. All ss were familiar with the on-the-job problems of child assessment and treatment. Applied Techniques of Child Care and Treatment was taught using a team approach. The team included Raymond Peterson, children's mental health specialist, Michael Ebner, Ph.D., clinical psychologist at the University of Portland and co-founder of Edgefield Lodge, a treatment facility for children, and Linda Peterson, video tape specialist and group process leader. 
The overall goal of the course was to enhance the effectiveness of those who work with children. Important components of this effectiveness were considered to be: 1) an increased awareness of one's impact on others and of one's personal characteristics; 2) an expanded understanding of emotionally disturbed and behaviorally complex children;

3) training in observation, "on the line assessment", and interpretation of events; 4) an introduction to the theory of child care, particularly in group and institutional settings; 5) experience in planning treatment intervention strategies; 6) expansion of one's awareness and skill in applied child caring and treatment techniques and 7) feedback on one's on-the-line practice while at the job.

A wide variety of approaches were used in the course methodology. Included were four key lectures: 1) the assessment of self; 2) the assessment of children and eco-systems; 3 ) personality types and response systems of workers and children and 4) observation and interpretation of behavior situations. Also used were class demonstrations and discussions based on child caring phenomena. Group exercises and role-plays were used to explore and analyze that phenomena. In addition video-taping of group exercises and role-play plus tapes of actual on-the-job interaction between student and child (when possible) provided further feedback and analys is from instructors and peers. Finally, audio cassettes in special areas of child care were presented. At all times the personal goals of the students were taken into account during the design of particular experiences involved in the course. (See appendix for student designed goals.)

The Ss were asked to write answers in the Problem Solving Situation 
(PSS) on the first day of class and acrin at the final class neeting. The PSS was designed by Michael Ebner for use at Edgefield Lodge to assess attitudes of parents. It involves four separate vignettes of problem situations with children in a child care setting. The $\underline{S}$ is asked to write how he/she would handle the situation and why. The time allowed to answer each vignette varies from 2 to 5 minutes. The Fall group received the same set of vignettes pre- and post-course. The Winter and Spring groups were given a revised set of four vignettes (PSS-R) post-course. Their pre-test vignettes were the same as those given to the Fall group. An example of the PSS and the PSS-R follows in figures 1 and 2.

The PSS and the PSS-R were scored according to the following response classes: Control, Placate and Punish, which are considered Worker Concern responses, and Child Aware, Self Aware and Child Care Technology, which are referred to as child Concern responses. The criteria for scoring each of the vignettes by the above response classes was as follows in figure 3 .

For each of the four vignettes, $\underline{S}$ answers were coded across all response classes on a scale of 0 to 3 . Such scoring for four vignettes yielded a possible range of 0 to twelve points for each of the 6 response classes. For the two groupings of 3 response classes each, Worker concern and child concern, there was a possible range of 0 to 36 . For the overall score from 6 responses classes there existed a range of 0 to 72 possible points. (An example of the coding sheet used to score each $\underline{S}^{\prime}$ 's response is in the appendix.) 
Vignette 1. (Complete your answer in five minutes).

You are a child care worker in a residential treatment center.

It is 8:00 P.M. You are in charge of un-cooperative young boys 7 to 9 years old. Characteristically, they have not been able to share, take turns, give and take, or cooperate with each other. Recently, however, they have been becoming gradually more able to do some of these things, though it doesn't take much to set them back to the old pattern. Today they have been very cooperative with each other, and the whole experience has been very useful. Now they are tired and irritable, and there is a scattering of equipment and general mess to clean up. To require them to do so might well end up in the erruption of a free for all. Yet, along the way you have been emphasizing the importance of looking out for the other guy and sharing equipment and space with the next guy. What would you do? Why would you do this?

Vignette II. (Complete your answer in two minutes.)

Later the same evening, one of the boys is running up and down the halls hitting kids and hollering. You command him to stop and he yells "Fuck you!" and he proceeds to tell one of the other boys to run down the hall and catch the keys he has grabbed from you. What would you do? Why would you do this?

Vignette III. (Complete your answer in two minutes.)

You did manage to get the group settled that night and left work at the end of your shift. You are on duty again the next morning. The boy who grabbed your keys last night and was such a problem, is quiet and goes about his business in an unobtrusive manner. You reassign unit duties and he is assigned the bathroom detail. He is pleasant and proceeds to do the job with no problems. What would you do and why would you do it?

Vignette IV. (Complete your answer in five minutes.)

That afternoon you re-read the file of the boy who took your keys and notice a report that indicates that this boy is basically shy and passive and needs to learn to become more self-assertive and expressive. In light of this information, would your behavior toward this boy have been different last night and this morning? How would it have been different last night? How would it have been different this morning? Why? 
Vignette 1. (Complete your answer in five ininutes.)

You are a child care worker in a residential treatment center. You are on the coast for an excursion with several boys from the 7 to 9 year old unit. They have never been particularly noted for fitting in well with schedules and handling requirements for unpleasant tasks. Today, however, they have been very cooperative in dealing with time limitations in moving from activity to activity, and they have generally been little gentlemen. They are now on the beach and it's getting to be time to tell them to stop playing in the surf and come in to clean up the cabin and prepare for dinner. After which, you will head back to the center, a considerable drive. They are strung out, tired, and having a ball. Requiring them to come in now is very likely to lead to a heavy hassle series, which could well undo the good experiences they've had today and lead to further difficulties. What would you do? Why would you do it?

Vignette 11. (Complete your answer in two minutes.)

It is now later, and everything is packed up and everyone is ready to return. Clean up and eating took longer than anticipated and its quite a bit later than it should be. Then one of the kids discovers the keys in the ignition and hides them somewhere in the area. He refuses to tell you where they are or to get them for you. What would you do? Why would you do it?

Vignette 111 . (Complete your answer in two minutes.)

Eventually, you managed to get the keys and get everyone back-very late. It is morning and a school day and everyone is having a hard time getting themselves ready for the day. The boy who hid the keys is quiet and goes about his business in an unobtrusive manner. You find he has cleaned up his section of his room and gone ahead and cleaned up the rest of his room for the other two, who are just not with it enough to do it this morning. What would you do? Why would you do it?

Vignette IV. (Complete your answer in five minutes.) The next day, you find out that the boy who hid the keys had received news the morning of the coast excursion that his parents were going to be divorced. In the light of this information, would your behavior toward him have been different on the coast? Why? How would it have been different the next morning? Why?

Figure 2. Problem Solving Situation (revised), PSS-R 
CONTROL

The response is concerned with the worker's control or foared loss of control. Also, the emphasis is on systems maintenance. The support systems involve things like routines, rules, schedules, plans, treatment programs, plant maintenance, sanitation, mealtimes and such.

\section{PLACATE}

The response is concerned with the possibility that if anything is asked of the children they will explode. So the worker "cops out" (leaves messes, does it himself, does not deal with the mess, problem, etc.). Be sure the statement(s) have this flavor. For example, not dealing with the problem may be an oversight as he concentrates on giving the children other valuable experiences.

\section{PUN ISH}

The response is centered on "stomping out sin". The worker intends to 1) get revenge, in general or for a particular event; 2) express moral indignation for a violation of a taboo; 3) squelch an assumed intention or motive by making it too painful to want to do that again; 4) activate a negative emotion or feeling such as pain, fear or guilt so response won't be repeated. The major consideration here is that it's the worker's intent, not the child's experience that gets top consideration. Some borderline cases may be scored here and in the child care technology response class (e.g., logical or natural consequences may be punitively employed).

\section{AWARENESS OF CHILD}

The emphasis here is either on the characteristics of the children or of their eco-systems, or on the experiences that the children will undergo as a function of the strategy being presented. These should reflect realistic estimations of real child phenomena, not worker belief systems. The worker's main concern is the welfare of the child and what's going on with him. This includes the ability to track events in the child's or children's eco-system.

\section{SELF AWARE}

The response reflects the worker's using purposefully information from his own experience or stimulus value, the worker's purposes being on behalf of the child.

\section{CHILD CARE TECHNOLOGY}

The worker uses specific tactics, strategies or techniques drawn from child caring response systems on behalf of the children. A wide range of skills are involved, including: The conscious use of self as a model; taking a problem solving approach regarding his own personal characteristics; the wise use of fun and humor; taking resourceful advantage of the characteristics of the environment at hand; and being efficient and relevant in his behavior.

Figure 3. Response classes used as criteria for coding the PSS \& PSS-R 
Method of Analys is of Data

For each response class a total score was determined across the 4 vignettes, pre- and post-. In addition, the sums of worker concern ratings and child concern ratings were determined. Finally, the sum of all the ratings (from six response classes) was determined and called the overall score.

The results were examined first by inspection of the frequencies and means of the pre- and post-scores. Differences in change scores were tested for significance by the t-test and correlated means. In addition to the raw scores, a ratio of child concern scores divided by total scores was used to examine the changes while controlling for variations in overall response frequencies.

Method for Testing Reliability

Tests of reliability were done on a sample of 5 pre-test and 5 post-test PSSS. Each of the ten samples were from different $\underline{\text { Ss. The }}$ researcher ( $B$ in table 1 ) and Michael Ebner ( $E$ in table 1 ) independently coded the responses. The frequency of the responses coded for each protocol are shown in Table 1.

Reading the table, the information is arranged by the number of times each coder scored a response zero, one, two, three, for all 10 PSSs. The reliabilities were estimated in two ways. First, on a presence or absence basis each protocol coded zero was then compared with each protocol scored one or more. Second, the mean value for all ten protocols were calculated and compared across the two coders.

On the basis of presence or absence of the response class in question, the pattern of agreement was as follows: Among worker concerns, 
there was relatively high agreement on both Placate and Punish response classes and relatively low agreement on Control. In the Placate response class one coder noted 5 zero responses and the second coder noted 6 , resulting in the first coder believing that 5 of the remaining protocols had scores of 1 or more and the second coder believing there were scores of one or more in 4 remaining protocols. This case represents high agreement. Likewise, in the Punish response class, both coders felt that 9 protocols had no such response class and each felt that one protocol had 1 such response, a case of perfect agreement.

In the Control response class, where agreement was lower, the first coder felt there were two protocols with no Control response, while the second coder felt there were 6 . Conversely, the first coder felt that 8 protocols had Control responses, while the second coder felt that 4 had not. This is a marked level of unreliability.

In the examination of the means for worker concern response classes, the Control category, again, reflects disagreement in that the mean score from the first coder is 1.1 and from the second coder is 0.4 . In the Placate responses, where the presence-absence agreement was high, the means are closer at 0.7 versus 0.4 . For the Punish response class, the means are the same, supporting the statement of perfect agreement indicated by the presence-absence level.

Among child concern responses, the presence-absence reliability calculation showed a high level of agreement for Child Aware with zero versus 1 for no response and 10 versus 9 for 1 or more responses. Child Care Technology also showed a high level of agreement in the presenceabsence analysis. Both coders felt that no protocols called for a score 
RELIABILITY OF RESPONSE CODING

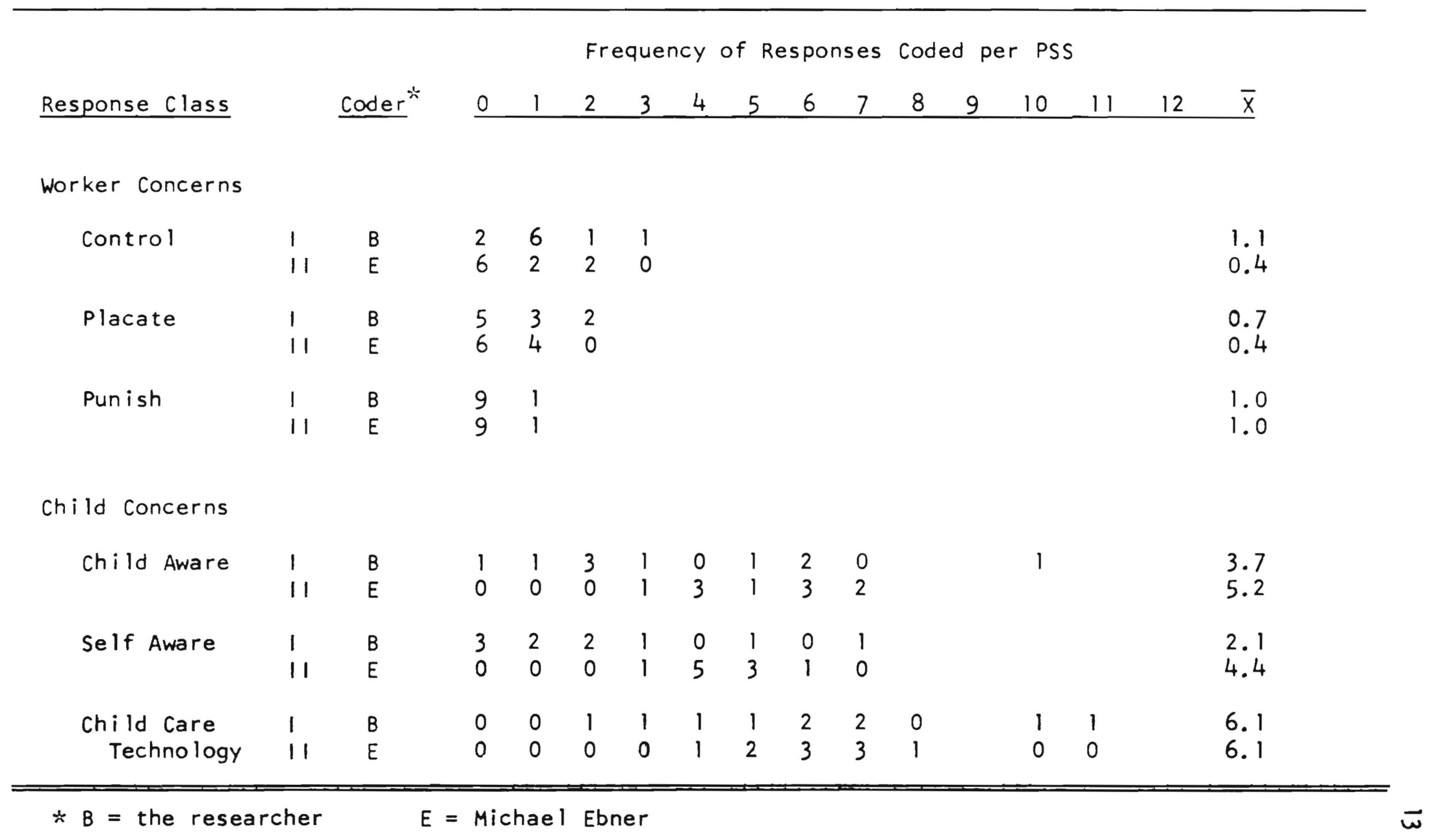


of zero; hence they universally agreed that all protocols had a score of 1 or more responses. On the Self Aware response class, the presenceabsence analysis showed low agreement in that the first coder felt 3 protocols had no response scoreable and 7 were scoreable while the second coder felt that all protocols were scoreable. Looking at the means for child concern responses, there is slightly less agreement in Child Aware than estimated by the presence-absence analysis. Coder 1 has a mean of 3.7 and coder 2 notes a mean of 5.2. In the area of Child Care Technology, there was absolute agreement on the mean value, both coders scoring a mean of 6.1 . It is interesting to note that that this is the one response class where coders used the widest range of scoring. In the Self Aware category the reliability estimate via the mean comparison showed one score to be twice that of the other.

Summing up then, the two ways of estimating reliability shows that there was fair to good agreement on two of the worker concern response classes and on one of the child concern response classes. Additionally, among Self Aware responses, there was excellent agreement on the presenceabsence analysis but only moderate agreement on the mean. Overall, it may be concluded that while there is some adequate reliability here, there is room for improvement. Such improvement could be achieved by further training and further preliminary comparison of interpretation of the response classes. 


\section{CHAPTER III}

\section{RFSULTS}

Looking at the raw data for all 30 Ss, Table II shows the pre- and post- frequencies and means of the responses coded for each protocol as well as the differences between pre- and post-mean scores. The layout shows these figures for each of the six response classes, for the two sub-groupings of the response classes, and the over-all scores. By inspection of Table II the following trends were evident: In the overall mean responses, Ss scored some 14 points in both the pre- and the posttests. For the worker concerns response classes, the modal response, pre- and post-, was zero with mean scores less than one. Slight increases on the post-test scores resulted in low change scores of about one-third of a point. Adding up across the three worker concern response classes, the pre-test mean was 1.39 , while the post-test mean increased slightly to 2.24 .

There were considerably more scores in each of the child concerns response classes. On both pre- and post-test scores, the modal response was four. Pre-test means were slightly higher than post-test means, resulting in low negative change scores of less than one-third of a point. Summing up scores across the three child concern response classes, there were almost 13 responses per $\underline{S}$ in the pre-test and almost 12 per $\underline{S}$ in the post-test, resulting in a decrease of almost one response.

Next, mean differences were subjected to two-tailed t-tests to assess possibly significant changes. T-tests for correlated means were used because the pre- and post-responses were by the same subjects, and, hence, were not independent. The procedure outlined in McNemar (Pg. 114) 
TABLE | |

PRE- AND POST- F'S AND $\bar{X}$ 'S OF CODED ANSWERS AND PRE- AND POST- $\bar{x}$ SCORE DIFFERENCES

\begin{tabular}{|c|c|c|c|c|c|c|c|c|c|c|c|c|c|c|c|c|c|c|c|c|}
\hline \multirow[b]{2}{*}{ Response Class } & \multicolumn{3}{|c|}{$\frac{\text { Pre-course }}{f^{\prime} s}$} & \multirow[b]{2}{*}{3} & \multirow[b]{2}{*}{4} & \multirow[b]{2}{*}{5} & \multirow[b]{2}{*}{6} & \multirow[b]{2}{*}{7} & \multirow[b]{2}{*}{8} & \multirow[b]{2}{*}{$\bar{x}$} & \multicolumn{4}{|c|}{$\frac{\text { Post-course }}{f^{\prime} s}$} & \multirow[b]{2}{*}{4} & \multirow[b]{2}{*}{5} & \multirow[b]{2}{*}{6} & \multirow[b]{2}{*}{7} & \multirow[b]{2}{*}{$\bar{x}$} & \multirow{2}{*}{$\begin{array}{l}\text { Pre and } \\
\bar{X} \text { diff }\end{array}$} \\
\hline & 0 & 1 & 2 & & & & & & & & 0 & 1 & 2 & 3 & & & & & & \\
\hline \multicolumn{21}{|l|}{ Worker Concerns } \\
\hline Control & 15 & 8 & 6 & 1 & & & & & & .73 & 17 & 8 & 1 & 1 & 2 & 1 & & & .87 & .13 \\
\hline Placate & 20 & 8 & 1 & 1 & & & & & & .43 & 17 & 6 & 6 & 0 & 0 & 0 & 1 & & .80 & .37 \\
\hline Punish & 23 & 7 & & & & & & & & .23 & 21 & 6 & 1 & 0 & 1 & 1 & & & .57 & .34 \\
\hline Total & & & & & & & & & & 1.39 & & & & & & & & & 2.24 & .85 \\
\hline \multicolumn{21}{|l|}{ Child Concerns } \\
\hline Child Aware & & & 2 & 6 & 10 & 8 & 3 & 1 & & 4.23 & 1 & 1 & 3 & 2 & 13 & 6 & 3 & 1 & 4.00 & -.23 \\
\hline Self Aware & & 1 & 2 & 6 & 18 & 3 & & & & 3.67 & 2 & 2 & 2 & 5 & 16 & 2 & 1 & & 3.37 & -.30 \\
\hline Child Care Tech & & & 2 & 2 & 7 & 11 & 5 & 2 & 1 & 4.83 & & 1 & 3 & 3 & 8 & 5 & 7 & 2 & 14.60 & -.23 \\
\hline Total & & & & & & & & & & 12.73 & & & & & & & & & 11.97 & -.76 \\
\hline Overall & & & & & & & & & & 14.12 & & & & & & & & & 14.21 & .09 \\
\hline
\end{tabular}


was used, in which pre-scores were subtracted from their post-scores. Table III shows the means of these difference scores, and the t-tests. None of the differences approached significance, as was indicated above by inspection of the slight differences in raw data.

Since there was some variation in overall frequencies of pre- and post-scores, it was thought that conversion of the child Concern scores to ratios per total scores for each $\underline{S}$ would eliminate any possible artifact. The ratio scores were calculated by dividing child concern scores by overall scores. Child Concern ratios were used to test the expected increases in these response classes. Changes were then calculated by subtraction of pre- from post-scores. To eliminate negative numbers, a constant of 1.0 was added to each ratio change figure. Scores thus calculated ranged from .498 to 1.210 .

Before examining the ratio score trends for the total group of 30 , it seemed possible that the Fall and Winter groups had higher scores than the Spring group. Thus, Fall and Winter groups were examined together because of the apparent similarity. Table IV shows the mean scores for the Fall and Winter versus the Spring groups. There we see the mean difference was slightly higher for the two earlier courses. The t-test for correlated means showed that there were no significant changes in the ratio. It is interesting to note that the mean change in the ratio score for the entire group, .903 , when converted back to the actual ratio by subtracting the 1.0 constant, yields a comparably low degree of change $(-.087)$, as had been previously found above in the examination of differences in raw scores. 
TABLE $\|$

MEANS OF DIFFERENCE SCORES AND THEIR T-TESTS

\begin{tabular}{|c|c|c|c|}
\hline & $\underline{X}$ & & \\
\hline Response Class & Difference & $\underline{t}$ & \\
\hline \multicolumn{4}{|l|}{ Worker Concerns } \\
\hline Control & .13 & .0019 & nst \\
\hline Placate & .37 & .0076 & ns \\
\hline Punish & .34 & .0061 & ns \\
\hline Total & .85 & .0052 & ns \\
\hline \multicolumn{4}{|l|}{ Child Concerns } \\
\hline Child Aware & -.23 & .0027 & ns \\
\hline Self Aware & -.30 & .0048 & ns \\
\hline Child Care Tech. & -.23 & .0027 & ns \\
\hline Total & -.76 & .0014 & ns \\
\hline Overall & -.09 & & ns \\
\hline
\end{tabular}


TABLE IV

RATIO CHANGE SCORES

\begin{tabular}{|c|c|c|c|c|}
\hline Term & $\underline{N}$ & $\frac{\text { Child Concerns }}{\bar{x} \text { difference in }} \begin{array}{c}\text { ratio scores }\end{array}$ & $\underline{t}$ & \\
\hline $\begin{array}{l}\text { Fall } 1972 \\
+ \\
\text { Winter } 1973\end{array}$ & 17 & .940 & .830 & nst \\
\hline Spring 1973 & 13 & .855 & 1.038 & ns \\
\hline Total & $\underline{30}$ &.$\underline{903}$ & .507 & ns \\
\hline
\end{tabular}

* Non-significant 
CHAPTER IV

\section{DISCUSSION}

The reader will recall that the main interest in attitude change was the movement from worker concerns to child concerns as a result of participating in the educational experience. Examination of the post course responses showed essentially no movement on any of the response classes. The worker concerns level of change was minimal, although it did increase slightly. Child concern scores decreased slightly, with $\underline{S s}$ scoring, on the average, about one third of the maximum score possible. On the surface, this lack of significant change may be seen as evidence that the course experience did not succeed in changing attitudes or knowledge. We cannot draw this conclusion with conviction, however, because of several possible difficulties with the design of the study and characteristics of the Problem Solving Situation assessment device.

Review of the data in the pre-test reflects that very few students were preoccupied with worker concerns initially and they responded about four times more frequently with child concerns. Thus, there was no room for decreases in those response classes. With another group who might start at a high level of worker concerns and a low level of child concerns there would be considerably more room on the instrument for a change. On the child concerns, students were getting about one third of the maximum score possible before having had the course. We do not know exactly what background factors may be reflected in this level of precourse knowledge. However, it seems quite possible that the $27 \mathrm{child}$ care workers in the study group were aided in analyzing the problems by their work experience. We do not know if similar pre-course answers 
might be given by persons with other or non-relevant backgrounds. We might also want to ask, are these responses "faked"? It is possible that $\underline{\text { Ss }}$ gave socially desirable answers regarding worker concerns since the expectation was for these concerns to decrease. There is less evidence of "faking good" on child concern responses, since both pre- and post-responses tended to fall in the lower one-third of the scale. It may also be true that the imposed time limit prevented ss from reflecting their full sophistication in their answers.

With the child concern response classes, the Ss were already sensitive to these approaches to children. However, there was considerable room for additional sophistication and movement in the measuring instrument. Students could have moved up another eight points on the average. Since they failed to do this, we may conclude that the exposure to the educational experience did not have an impact on child concerns. Or it may be that the PSS format or coding criteria were insensitive to $\underline{S}$ change.

Some difficulties with coding the instrument have been discussed in the Method section of this study. It was concluded that, while some adequate reliability existed, improvement could be achieved by additional training for the coders, such as by further preliminary comparison how they interpret the response classes. An issue of concern, whether the researcher had adequately and competently used the potential range available for the criterion of scoring, was dispelled. Inasmuch as the researcher did not score so conservatively as to unnecessarily or invalidly truncate the variance of the ratings assigned to the protocols. In regard to the slight increase in the placate response class, it 
should be noted that there is an overlapping variable in the criteria for coding this response in that responses that appear to be avoidance on the part of the worker to deal with the problem may be the worker's attempt to deal with what seem to be more important experiences for the child given the context. In that case the response could have been coded in the Child Care Technology response class. A similar coding difficulty exists between the Punish response class and Child Care Technology in regard to the use of natural consequences to teach new behaviors. So much for problems with the PSS as an assessment devide.

Next are considerations about the design. The comparisons made in this study might have been enhanced by the use of one or more control groups consisting of similar and different kinds of people.

It should be noted that what appeared to be an "anti-intellectual bias" on the part of the majority of this group of students was observed by the senior instructor, Michael Ebner. This "bias" manifested itself in a resistance to analyzing and composing answers to the PSS. If such a bias did indeed exist, it could have diminished the sophistication with which the Ss expressed themselves and their willingness to participate twice in the same testing experience.

\section{Recommendations}

A number of points can be made on how to improve this type of research. The major focus should be on the nature and limitations of the coding of responses to the four vignette problems. First, this modality of evaluation taps into cognitive and attitudinal factors divorced from the live work situation. Therefore, it would be of considerable value to assess actual problems or even simulated problems. This, in 
lact is being done in the course ongoing at the time of this writing. Students are presented with actual video taped child care problems and asked to spontaneously respond to "what's happening?" Although this approach falls short of observing the worker in an actual work situation, it moves the worker and the examiner much closer to reality than a paper and pencil test.

Another possible problem with the vignette approach may have been in the number of vignettes used. Using four different problem situations may not have been adequate as a base of measurement. Generally speaking, the fewer the number of items in a test the less reliable it is. Here we are dealing with a four item test that has been scored across six different response classes. That may be an undue amount of analys is from a limited original data base.

Also, the same vignettes were used both pre- and post-test in the Fall group. The opportunity for direct recall of the learning experience, if any, existed. However, the data do not reflect that potential impact. There are no controls for the background of the students or the intervening activities that the students engaged in during the term, including contact among class members or other exposures that may have enhanced or detracted from their competency. Also, there needs to be systematic variation or control of teacher behavior. We have no observations of the actual range of methods used within the course to assure complete consistency of methodology across the three terms or within any one term. While the same course plan and the same instructors were used for the three repetitions of the course, it cannot be validated that the exact methodology and the exact amount of time spent on various topics was consistent across the study groups. It should be noted, too, that a 
disproportionate number of respondents were available from the spring group (13) compared to the other two groups (17).

Finally, while the data collected and analyzed in this study did not indicate a substantial change in the attitudes of $\underline{S s}$, we cannot state that the course was without impact. Indeed, results of a course Impact Assessment taken by the students at the end of each term indicated a general satisfaction with the course. (See sample of Course Assessment Device in the appendix.) Unlike the PSS, minimal analys is and no composition was required of the $\underline{S s}$ in responding to structured rating scales. Also, the only writing requested was a feeling level statement from the $\underline{S}$ about themselves. (In the PSS the target topic was the child presenting a problem.) Since the $\underline{S s}$ in this study appeared more willing to participate in answering this kind of assessment device, it is suggested that further analysis of the data collected using the Course Impact Assessment be done.

In conclusion, this researcher feels that a significant contribution to the literature that is relevant to the training of child care workers by adult education programs has been made in the presentation of this research practicum. 


\section{REFERENCES}

Becker, Jerome (ed.) Critical Incidents in Child Care. New York: Behavioral Publications, Inc., 1973.

Bryant, A. A., Bryant, B. F., Christiansen, D., Fisher, L. 1971. "The Effectiveness of Taped Reading Instruction in Increasing the Reading Comprehension of Undereducated Adults," Adult Education Journal, XX1, 4, 246-252.

DiSalvi, R. D. 1971. "A Remedial Program for Undergraduate Evening Students," Adult Education Journal, XXI, 3, 186-195.

Dickson, Gary \& Rubidge, Nicholas A. 1973. "Testing Knowledge About Adult Education," Adult Education Journal, XX111, 4, 283-297.

Dickinson, Gary \& Russe1, Dale. 1971. "A Content Analys is of Adult Education," Adult Education Journal, XXI, 3, 177-195.

Dreikers, Rudolph, Challenge of Parenthood. New York: Duell, Sloan $\varepsilon$ Pearce, 1948.

Ebner, Michael J. Randy: A Functional Analys is, unpublished manuscript, 1966.

Ebner, Michael J. Know Your Response Class, unpublished manuscript, 1969.

Ebner, Michael J. Functional Analys is: A New Approach to Assessment, unpublished manuscript, 1972.

Ebner, M. J. E Murray, W. A. So You Want to Work with Kids? Unpublished manuscript, 1972.

Ebner, M. E Peterson, R. (eds.) Techniques and Situations in Child Care by Child Care Workers, unpublished manuscript, 1972 .

Endres, Mary P. \& Evans, Merry J. 1968. "Some Effects of Parent Education on Parents and Their Children," Adult Education Journal, XVII1, 2, 101-111.

Essert, Paul L. Creative Leadership of Adult Education. New Jersey: Prentice-Hall, 1951.

Ginott, Heim. Between Parent and Child. New York: Macmillan, 1965.

Goodacre, D. M. 1957. "The Experimental Evaluation of Management Training: Principles and Practice," Personnel, B. F. Goodrich Co., 1957. 
James, Muriel \& Jongeward, Dorthey. Born to Win: Transactional Analys is with Cestalt Experiments. Menlo Park, California: Addison-Wesley Publishing Co., 1971.

Johnson, R. L., Cortright, R. W. E Cooper, J. 1968. "Attitudes Changes Among Literacy Teachers Coincident with Training and Experience," Adult Education Journal, XVIII, 2, 71-80.

Knowles, M. J. Informal Adult Education. New York: Association Press, 1950 .

Knowles, M. J. The Modern Practice of Adult Education. New York: Association Press, 1970.

Mayer, Morris F. A Guide for Child-Care Workers. New York: The Child Welfare League of America, Inc., 1958.

McNemar, Quinn. Psychological Statistics. New York: Wiley, 1949.

Patterson, Gerald E Gullion, M. Elizabeth. Living With Children. Champaign, Illinois: Research Press, 1968.

Robinson, R. E Spraights, E. 1969. "A Study of Attitudinal Change Through Lecture-Discussion Workshops," Adult Education Journal, $x \mid x, 3,163-171$.

Sabrosky, Laurel. "In Evaluation," The Cooperative Extension Service. New Jersey: Prentice-Hall, 1966.

Satir, Virginia. People Making. Palo Alto, California: Science $E$ Behavior Books, 1972.

Thatcher, John. In "Evaluation", Public School Adult Education: A Guide for Administrators. Washington, D.C.: National Education Association, 1963.

Verner, Coolie E Booth, Alan. Adult Education. New York: Center for Applied Research in Education, 1964.

Walpole, R. E. Introduction to Statistics. London: Collier-Macmillan Limited, 1968.

Watson, Eugene. 1962. "Interpersonal Changes Through Immediate Feedback Approaches," Adult Education Journal, XIX, 4, 251-267.

Weber, G. H. E Haberlein, B. J. (eds) Residential Treatment of Emotionally Disturbed Children. New York: Behavior Publications, Inc., 1973.

, Training for Child Care Staff. New York: Child Welfare League of America, Inc., 1963. 
APPEND IX ।

STUDENT-DES IGNED GOALS FOR COURSE

1. Diagnostic Assessment

2. Techniques of Intervention

3. Public Relations and Relating to Parents

4. 1-to-1 Work and Crisis Intervention

5. Positive Reinforcement - Its Use and Role

6. Non-Verbal Behavior

7. Assessing the Effectiveness of the Worker

8. Working thru Losses - Child and Worker

9. Self-Respect Induction

10. Individual vs. Group Considerations

11. Unwilling Kid in Treatment

12. Angry, Aggressive Children

13. Limits and Standards

14. When, How Much, and How to Punish

15. Relationship Usage

16. General Approaches (Theories)

17. What Do we Train Kids to Do (Be)?

18. How to Tell what kid is Experiencing

19. Realities of "My" Kids - Their Ecosystem and the Problem of Worker Possessiveness and Overinvestment

20. Family Work

21. Human Needs vs. Treatment Programs

22. Agency vs. Kids vs. Worker vs. School vs. Family

23. Self Awareness (Worker)

24. Self Awareness (Child) 
APPENDIX I।

CODING SHEET

\begin{tabular}{|c|c|c|c|c|c|}
\hline \multirow[b]{2}{*}{ VAR IABLES } & \multicolumn{5}{|c|}{ SUBJECT_ } \\
\hline & VIGNETTE & BEFORE & TOTAL & AFTER & TOTAL \\
\hline \multirow[t]{3}{*}{ Control } & 1 & 01223 & & 0123 & \\
\hline & I I & 0123 & & 0123 & \\
\hline & 111 & 0123 & & 0123 & \\
\hline . & IV & $\begin{array}{llll}0 & 1 & 2 & 3\end{array}$ & & 01233 & \\
\hline \multirow[t]{4}{*}{ Placate } & 1 & $\begin{array}{llll}0 & 1 & 2 & 3\end{array}$ & & 01123 & \\
\hline & 11 & 0123 & & 0123 & \\
\hline & II I & 0123 & & 0123 & \\
\hline & IV & 0123 & & 0123 & \\
\hline \multirow[t]{4}{*}{ Pun ish } & 1 & 0123 & & 0123 & \\
\hline & 11 & 0123 & & 0123 & \\
\hline & 111 & 0123 & & 0123 & \\
\hline & IV & 0123 & & 0123 & \\
\hline \multirow[t]{4}{*}{ Child Aware } & 1 & 0123 & & 0123 & \\
\hline & I & 0123 & & 0123 & \\
\hline & 111 & 0123 & & 0123 & \\
\hline & IV & 0123 & & 0123 & \\
\hline \multirow[t]{4}{*}{ Self Aware } & 1 & 0123 & & 0123 & \\
\hline & 11 & 0123 & & 0123 & \\
\hline & 111 & 0123 & & 0123 & \\
\hline & IV & 0123 & & 0123 & \\
\hline \multirow[t]{4}{*}{ Child Care Tech. } & 1 & 0123 & & 0123 & \\
\hline & 11 & 0123 & & 0123 & \\
\hline & $|1|$ & 0123 & & 0123 & \\
\hline & IV & 0123 & & 0123 & \\
\hline
\end{tabular}

Student

Ma le

Fema le

Emp loyed

Grad.

Undergrad.

CCW SW Student 


\section{COURSE IMPACT ASSESSMENT}

1. How would you describe the overall impact the course had on you? Please be specific.

2. Describe in what ways, if any, the course experiences may have made a change in your personal growth. Explain how you changed, in what areas of life, etc.

2a. Now would you rate the amount of your personal growth? Put an " $x$ " on the line at the place which most closely describes the amount of your personal growth.

\begin{tabular}{|c|c|c|c|c|}
\hline 1 & & 3 & 4 & 5 \\
\hline $\begin{array}{l}\text { Destructive } \\
\text { of my personal } \\
\text { growth }\end{array}$ & $\begin{array}{l}\text { Some aspects } \\
\text { were growth- } \\
\text { enhancing; } \\
\text { others eroded }\end{array}$ & $\begin{array}{l}\text { Had no real } \\
\text { effect on my } \\
\text { personal } \\
\text { growth }\end{array}$ & $\begin{array}{l}\text { Most ly growth } \\
\text { enhanc ing }\end{array}$ & $\begin{array}{l}\text { Extreme ly } \\
\text { growth } \\
\text { producing }\end{array}$ \\
\hline
\end{tabular}
my personal growth

2b. If you wish, you may use this space to explain, expand, or clarify your rating on this aspect of the impact of the course.

3. Describe in what ways the course experiences made a change in your work role(s). Has your role altered in your work? If so, in what ways? Be as specific as possible.

3a. Now would you please rate the amount to which your work role has changed. Put an " $X$ " on the line at the place which most closely describes the amount of change in your work role.

\begin{tabular}{|c|c|c|c|c|}
\hline 1 & $1_{1}^{2}$ & & 4 & 5 \\
\hline $\begin{array}{l}\text { I have become } \\
\text { less effective } \\
\text { in my work role }\end{array}$ & $\begin{array}{l}\text { Some aspects } \\
\text { of my work role } \\
\text { have changed; } \\
\text { others have } \\
\text { deteriorated }\end{array}$ & $\begin{array}{l}\text { Had no real } \\
\text { impact on my } \\
\text { work role }\end{array}$ & $\begin{array}{l}\text { My work role } \\
\text { has been } \\
\text { mostly in- } \\
\text { creased in } \\
\text { effect ive- } \\
\text { ness }\end{array}$ & $\begin{array}{l}\text { Extremely } \\
\text { enhancing } \\
\text { to my work } \\
\text { role }\end{array}$ \\
\hline
\end{tabular}

3b. If you wish, you may use this space to explain, expand, or clarify your rating on this aspect of the impact of the course.

4. Describe in what ways (if any) the course experience made a change in your concepts and orientation to child care and treatment-relevant issues. What concepts and orientations were affected? How were they changed? What were the most important new concepts you learned? 
4a. Now would you please rate the amount to which your concepts and orientations have changed. Put an " $X$ " on the line at the place which most closely descrlbes the allount of change in your thinhing.

\begin{tabular}{|c|c|c|c|c|}
\hline 1 & 2 & 3 & 14 & 5 \\
\hline $\begin{array}{l}\text { Confused and } \\
\text { unsett led } \\
\text { what I knew }\end{array}$ & $\begin{array}{l}\text { Learned no new } \\
\text { concepts; no } \\
\text { change in orien- } \\
\text { tation }\end{array}$ & $\begin{array}{l}\text { Mainly a } \\
\text { refresher of } \\
\text { what I knew; } \\
\text { learned a few } \\
\text { new concepts }\end{array}$ & $\begin{array}{l}\text { Learned a } \\
\text { number of } \\
\text { new concepts; } \\
\text { orientation } \\
\text { significant- } \\
\text { ly changed }\end{array}$ & $\begin{array}{l}\text { Opened a } \\
\text { whole new } \\
\text { world of } \\
\text { concepts and } \\
\text { orientation }\end{array}$ \\
\hline
\end{tabular}

4b. If you wish, you may use this space to explain, expand or clarify your rating on this aspect of the impact of the course.

5. Describe in what ways (if any) the course experience made a change in your skills and approaches to intervention with children. What skills and approaches did you learn? What approaches do you use less now? Why have you made these changes?

5a. Now would you please rate the amount to which your skills and approaches have changed. Put an " $X$ " on the line at the place which most closely describes the amount of change in your skills and approaches.

\begin{tabular}{|c|c|c|c|c|}
\hline 1 & 2 & 3 & 4 & 5 \\
\hline $\begin{array}{l}\text { Disrupted my } \\
\text { functioning }\end{array}$ & $\begin{array}{l}\text { My skills } \\
\text { and approaches }\end{array}$ & $\begin{array}{l}\text { Pretty much } \\
\text { a validation }\end{array}$ & $\begin{array}{l}\text { Learned a } \\
\text { number of new }\end{array}$ & $\begin{array}{l}\text { My whole } \\
\text { style changed }\end{array}$ \\
\hline with children & $\begin{array}{l}\text { were not rea }- \\
\text { ly affected }\end{array}$ & $\begin{array}{l}\text { of what l've } \\
\text { been doing; } \\
\text { learned a few } \\
\text { new skills }\end{array}$ & $\begin{array}{l}\text { skills and } \\
\text { approaches; } \\
\text { my sty le was } \\
\text { significantly } \\
\text { changed }\end{array}$ & $\begin{array}{l}\text { I'm constant- } \\
\text { ly using the } \\
\text { new skills and } \\
\text { approaches I } \\
\text { learned }\end{array}$ \\
\hline
\end{tabular}

5b. If you wish, you may use this space to explain, expand or clarify your rating on this aspect of the impact of the course.

6. Please indicate the experiences you found the most useful. What was their impact? Why were they useful to you? Where does their impact show up? 
7. Please indicate the experiences in the course which you found least useful. What effect did they have at the time? Why were they not very useful to you? What about them made them irrelevant or detrimental to you?

8. If you were to design the course, what changes would you make? Think inclusively and specifically. For instance, the format, instructors, content, timing or sequencing of the experiencing, location-setting, time and duration of the meetings, methods, assignments, resources, etc.

9. Have you any other comments, suggestions, information, etc. that you would like us to know?

10. What was your state of mind while filling out this assessment? How turned off by the structure of the content of effort of it were you? Were there any questions that you really turned on to and why? Were there any that you just slopped through, why? Are there any additional questions or other approaches you would suggest to assess the impact of the course? 